\title{
Effect of Normalizing and Hardening on Mechanical Properties of Spring
}

\author{
O. R. Adetunji', P. O. Aiyedun, S. O. Ismaila, M. J. Alao \\ Mechanical Engineering Department, College of Engineering, Federal University of Agriculture, Abeokuta, Nigeria \\ Email: *adetunjiolayide@yahoo.co.uk
}

Received May 27, 2012; revised July 7, 2012; accepted July 30, 2012

\begin{abstract}
This study was carried out to investigate the effect of heat treatment (Normalizing and Hardening) on the mechanical properties of springs. The springs were made from mild steel rod having a diameter of $6 \mathrm{~mm}$, a total of 15 springs were made. The springs were then subjected to various heat treatment processes which included; normalizing, hardening and tempering. The heat treated springs were then subjected to various test in other to determine their mechanical properties, these included; impact toughness test, hardness test and tension test. The normalized spring had more strength, was harder and was much tougher than both the annealed and as received springs. The water quenched springs were the hardest of all the heat treated springs, were very brittle and had the lowest percentage elongation. Their strength was also lower than that of the normalized and as received springs. The water quenched and tempered springs had better mechanical properties required for spring making, they had the optimum combination of hardness, strength and toughness when compared with the other heat treated springs.
\end{abstract}

Keywords: Normalizing; Hardening; Tempering; Impact Toughness; Tension; Spring

\section{Introduction}

A spring is defined as an elastic body, whose function is to distort when loaded and to recover to its original shape when the load is removed. The various important applications of springs are as follows:

a) To cushion, absorb or control energy due to either shock or vibration as in car springs, railway buffers, aircraft landing gears, shock absorbers and vibration dampers.

b) To apply forces as in brakes, clutches and spring loaded valves.

c) To control motion by maintaining contact between two elements as in cams and followers.

d) To measure forces as in spring balances and engine indicators.

e) To store energy as in watches.

There are various types of springs theses are: coil springs, leaf springs, torsion bars and air springs [1].

1) Coil springs: is a mechanical device which is typically used to store energy and subsequently release it to absorb shock, or to maintain a force between contacting surfaces.

2) Leaf springs: are suspension springs made up of several thin, curved, hardened-steel or composite-mate-

\footnotetext{
*Corresponding author.
}

rial plates attached at the ends to the vehicle underbody.

3) Torsion bars: are a long straight steel bar fastened to the chassis at one end and to a suspension part at the other which when twisted provides the spring force.

4) Air springs: is a mechanical device using confined air to absorb the shock of motion?

\subsection{Heat Treatment}

This is the heating and cooling of a solid metal or alloy in such a way as to obtain desired conditions or properties. The term heat treatment process is in and of itself only a very generic term; it covers all specific methods [2]. Thus emphasis will be made on those forms of heat treatment that are most commonly used in the spring industry these are: Annealing, Normalizing, Hardening and Tempering.

\subsection{Normalizing/Stress Relieving}

Heating to a suitable temperature, holding long enough to reduce residual stresses, and then cooling slowly enough to minimize the development of new residual stresses. It relieves the stresses that occur as a result of the spring forming operation. It also returns the material to the strength levels prior to the forming operation and can 
actually increase the strength to levels greater than originally supplied [3].

The normalizing of steel is carried out by heating approximately $100^{\circ} \mathrm{F}\left(38^{\circ} \mathrm{C}\right)$ above the upper critical temperature (Ac3 or Acm) followed by cooling in air to room temperature Normalizing is often considered from both a thermal and a micro structural standpoint. In the thermal sense, normalizing is austenitizing followed by a relatively slow cooling.

\subsection{Hardening (Water Quenching)}

Quenching can be done by plunging the hot steel in water. The water adjacent to the hot steel vaporizes, and there is no direct contact of the water with the steel. This slows down cooling until the bubbles break and allow water contact with the hot steel. Water quenching produces steel with a very high hardness but also results in very brittle and fragile steel with a low tensile strength also. As the water contacts and boils, a great amount of heat is removed from the steel. With good agitation, bubbles can be prevented from sticking to the steel, and thereby prevent soft spots. Water is a good rapid quenching medium, provided good agitation is done. However, water is corrosive with steel, and the rapid cooling can sometimes cause distortion or cracking [3].

\subsection{Tempering}

Tempering is usually done after quenching, it involves re-heating of the steel in order to reduce the hardness of the quenched steel and improve the ductility, toughness and strength of the spring. Tempering is usually done hand in hand with quenching and is usually a tradeoff between hardness and toughness/strength of steel. This research is aimed at evaluating the effect of normalizing, hardening and tempering on the impact toughness, hardness and tensile strength of springs.

\section{Experimental Methodology}

The springs were made using mild steel rods having a diameter of $6 \mathrm{~mm}$. The following were the steps taken during the making of the springs. The mandrel and one end of the steel rod were clamped together with the use of a g clamp. The steel rod was clamped to the beginning of the mandrel [4-6].

a) The steel rod was then wound round the mandrel at the desired pitch.

b) When the desired number of turns was reached i.e. 8 turns. The steel rod was then cut off from the unwound steel rod with the help of a saw.

c) The mandrel with the spring wound round it was both removed from the g-clamp after which the spring was removed from the mandrel.

\subsection{Normalizing/Stress Relieving}

In normalizing the springs were heated to $550^{\circ} \mathrm{C}, 700^{\circ} \mathrm{C}$ and $900^{\circ} \mathrm{C}$ respectively, after the desired temperature had been obtained they were removed from the furnace and allowed to cool in air till room temperature was obtained. They will have a different property if the springs have cooled down to room temperature in the furnace.

\subsection{Hardening (Water Quenching)}

In water quenching the springs were heated to about $850^{\circ} \mathrm{C}$ to ensure conversion to austenite had been achieved. The springs were then taken out of the furnace and placed in a bath of water to ensure that rapid cooling of the spring occurred.

\subsection{Tempering}

In tempering the three water quenched steel were heated to $300^{\circ} \mathrm{C}, 500^{\circ} \mathrm{C}$ and $600^{\circ} \mathrm{C}$ respectively and were then allowed to cool down gradually. This was done to relieve some of the stress that occurred during water quenching and to also reduce the hardness of the steel rod, thus making it more tougher.

The remaining three springs were not subjected to any heat treatment and shall thus be used for comparison with the other heat treated springs.

Three new set of springs are normalized, this is done by heating them to the following respective temperature $550^{\circ} \mathrm{C}, 700^{\circ} \mathrm{C}$ and $850^{\circ} \mathrm{C}$ after which they are removed from the furnace and allowed to cool in air to atmospheric temperature.

1) Three new set of springs are then heated to $850^{\circ} \mathrm{C}$ after which they are removed from the furnace and placed in a bath of water, a process known as water quenching.

2) The three set of springs which have been water quenched from $850^{\circ} \mathrm{C}$ are then tempered by heating them to the following temperature $300^{\circ} \mathrm{C}, 500^{\circ} \mathrm{C}$ and $600^{\circ} \mathrm{C}$ respectively after which they are allowed to cool at a slow rate.

\subsection{Impact Toughness}

The impact test is done with an impact tester. This is used to determine toughness of the steel wire used for the spring the impacter was allowed to fall from a certain height in other to crush the steel rod. The height from which the impacter is released can be used to measure the degree of hardness of the steel rod by the amount of energy absorbed by the rod before fracture.

\subsection{Tensile Test}

The tensioning machine was used to determine the strength of the spring. A force is applied axially via 
weights on the tensioning machine. The amount of force required to produce a certain amount of deflection was then recorded for all the spring samples.

\subsection{Hardness Test}

The surface hardness test was measured by Matsuzawa DXT3 Rockwell test device according to the ISO standards, this was done to determine the hardness of the various heat treated springs. The water quenched spring was subjected to an incremental load of $4 \mathrm{~kg}$ and an extension of $0.15 \mathrm{~cm}$ was measured until an extra load of $4 \mathrm{~kg}$ was added to the $16 \mathrm{~kg}$ mass and an extension of $0.3 \mathrm{~cm}$ was measured, which indicated that $16 \mathrm{~kg}$ was the yield load of the water quenched springs, similarly the yield load of the normalized and as received springs can be obtained from Section 3 (Result and Discussion).

\section{Result and Discussion}

The results obtained for tension test of normalized springs are contained in Table 1, tension test for water quenched, tempered and as received springs in Table 2, impact toughness and hardness test for normalized springs in Table 3 and impact toughness and hardness test for hardened and tempered springs in Table 4.

Table 1. Tension test for normalized springs.

\begin{tabular}{cccc}
\hline $\begin{array}{c}\text { Load } \\
(\mathrm{kg})\end{array}$ & $\begin{array}{c}\text { Extension }(\mathrm{cm}) \\
\text { Normalized at } \\
550^{\circ} \mathrm{C}\end{array}$ & $\begin{array}{c}\text { Extension }(\mathrm{cm}) \\
\text { Normalized at } \\
700^{\circ} \mathrm{C}\end{array}$ & $\begin{array}{c}\text { Extension }(\mathrm{cm}) \\
\text { Normalized at } \\
850^{\circ} \mathrm{C}\end{array}$ \\
\hline 4 & 0.5 & 0.6 & 0.5 \\
8 & 1.0 & 1.2 & 1.0 \\
12 & 1.5 & 1.8 & 1.5 \\
16 & 2.0 & 2.4 & 2.0 \\
20 & 2.7 & 3.3 & 2.5 \\
\hline
\end{tabular}

Table 2. Tension test for water quenched, tempered and as received springs.

\begin{tabular}{cccccc}
\hline Load (kg) & $\begin{array}{c}\text { Extension (cm) Water } \\
\text { Quenched at } 850^{\circ} \mathrm{C}\end{array}$ & $\begin{array}{c}\text { Extension (cm) Tempering } \\
\text { at } 300^{\circ} \mathrm{C}\end{array}$ & $\begin{array}{c}\text { Extension (cm) Tempering } \\
\text { at } 500^{\circ} \mathrm{C}\end{array}$ & $\begin{array}{c}\text { Extension (cm) Tempering } \\
\text { at } 600^{\circ} \mathrm{C}\end{array}$ & $\begin{array}{c}\text { As Received } \\
\text { spring }\end{array}$ \\
\hline 4 & 0.15 & 0.45 & 0.55 & 0.6 & 0.4 \\
8 & 0.3 & 0.9 & 1.1 & 1.2 & 0.8 \\
12 & 0.45 & 1.3 & 1.6 & 2.4 & 1.8 \\
16 & 0.6 & 1.7 & 2.1 & 3.0 & 2.0 \\
20 & 0.9 & 2.0 & 2.8 & 3.8 & 2.6 \\
24 & & 2.5 & & & 3.6 \\
\hline
\end{tabular}

Table 3. Impact toughness and hardness test for normalized springs.

\begin{tabular}{cccccccc}
\hline S/No & Spring Description & $\begin{array}{c}\text { YL } \\
(\mathrm{kg})\end{array}$ & $\begin{array}{c}\text { Yield Stress } \\
(\mathrm{kg} / \mathrm{mm})\end{array}$ & $\begin{array}{c}\text { Extension } \\
(\mathrm{cm})\end{array}$ & \% Elongation & $\begin{array}{c}\text { Toughness } \\
\text { (Joules) }\end{array}$ & $\begin{array}{c}\text { Hardness } \\
(\mathrm{RC})\end{array}$ \\
\hline 1 & Normalized at 550 & 16 & 0.555 & 2.4 & 25 & 45 & 50 \\
2 & Normalized at 700 & 16 & 0.555 & 3.0 & 30 & 49 & 47 \\
3 & Normalized at 850 & 24 & 0.848 & 3.0 & 37.5 & 58 & 38 \\
\hline
\end{tabular}

Table 4. Impact toughness and hardness test for hardened and tempered springs.

\begin{tabular}{|c|c|c|c|c|c|c|c|}
\hline S/No & Spring description & $\begin{array}{c}\text { YL } \\
(\mathrm{kg})\end{array}$ & $\begin{array}{l}\text { Yield Stress } \\
(\mathrm{kg} / \mathrm{mm})\end{array}$ & $\begin{array}{l}\text { Extension } \\
\quad(\mathrm{cm})\end{array}$ & \% Elongation & $\begin{array}{c}\text { Toughness } \\
\text { (Joules) }\end{array}$ & $\begin{array}{l}\text { Hardness } \\
\text { (Rc) }\end{array}$ \\
\hline 1 & Water quenched at 850 & 16 & 0.565 & 0.6 & 7.5 & 20 & 49 \\
\hline 2 & Tempered at 300 & 20 & 0.565 & 1.7 & 21.25 & 47 & 45 \\
\hline 3 & Tempered at 500 & 16 & 0.707 & 2.6 & 32.25 & 55 & 38 \\
\hline 4 & Tempered at 600 & 20 & 0.565 & 2.4 & 31 & 45 & 35 \\
\hline
\end{tabular}




\subsection{Normalized Springs}

As the steel is heated above the critical temperature, about $1335^{\circ} \mathrm{F}\left(724^{\circ} \mathrm{C}\right)$, it undergoes a phase change, recrystallizing as austenite. Continued heating to the hardening temperature, $1450^{\circ} \mathrm{F}-1500^{\circ} \mathrm{F}\left(788^{\circ} \mathrm{C}-816^{\circ} \mathrm{C}\right)$ ensures complete conversion to austenite. At this point the steel is no longer magnetic, and its color is cherry-red, normalizing has a slower rate of cool than annealing and this accounts for the springs having a greater strength than the annealed spring, and also accounts for it being harder and less ductile than the annealed springs $[7,8]$.

\subsection{Hardening and Tempering}

As the steel is heated above the critical temperature, about $1335^{\circ} \mathrm{F}\left(724^{\circ} \mathrm{C}\right)$, it undergoes a phase change, recrystallizing as austenite (i.e. it changes from body centered cubic to face centered cubic) Continued heating to the hardening temperature, $1450^{\circ} \mathrm{F}-1500^{\circ} \mathrm{F}\left(788^{\circ} \mathrm{C}\right.$ $816^{\circ} \mathrm{C}$ ) ensures complete conversion to austenite, the springs are then cooled suddenly by quenching in a bath of water, a new crystal structure, martensite, is formed as seen in the micro structural analysis above. Martensite is characterized by an angular needle-like structure and very high hardness, as seen from the hardness test carried out. While martensitic steel is extremely hard, it is also extremely brittle and will break, chip, and crumble with the slightest shock. Furthermore, internal stresses remain in the spring from the sudden quenching; these will also facilitate breakage of the spring. Tempering relieves these stresses and causes partial decomposition of the martensite into ferrite and cementite. The amount of this partial phase change is controlled by the tempering temperature. The tempered steel is not as hard as pure martensite, but is much tougher. This can be observed from the result tabulated above where by the water quenched sprigs have the highest hardness and are the least ductile from all the springs, but after the water quenched steel were tempered it was observed that the hardness of the spring reduced, the toughness and ductility increased when compared to the water quenched springs.

\section{Conclusions}

The normalized spring had more strength, was harder and was much tougher than as received springs.

The water quenched springs were the hardest of all the heat treated springs, were very brittle and had the lowest percentage elongation. Their strength was also lower than that of the normalized and as received springs.

The tempered water quenched springs had better mechanical properties required for spring making, they had the optimum combination of hardness, strength and toughness when compared with the other heat treated springs.

\section{REFERENCES}

[1] W. Harris, “How Car Suspensions Work,” 2005. http://auto.howstuffworks.com/car-suspension.htm

[2] E. T. George, "Steel Heat Treatment: Metallurgy and Technologies,” CRC Press, Boca Raton, 2006.

[3] R. A. Higgins, "Engineering Metallurgy Hodder and Stoghton,” London, 1980.

[4] T. D. Gillespie, "Fundamentals of Vehicle Dynamics," Society of Automotive Engineers, New York, 2009.

[5] T. Kadrinm, “ASM Materials Engineering Dictionary,” ASM International, 1992. www.asminternal.org

[6] H. Loretta, "How to Make Springs," 2000. http://home.earthlink.net/-bazillion/intro.html

[7] J. M. Pellizzari, M. Zadra and A. Molinari, "Tribological Properties of Surface Engineered Hot Work Tool Steel for Aluminum Extrusion Dies,” Surface Engineering, Vol. 23, No. 3, 2007, pp. 165-168. doi:10.1179/174329406X150477

[8] O. A. Fayol, C. A. Boher, R. B. Gras and F. A. RezaiAria, "Analysis of the Friction and Wear Behavior of Hot Work Tool Steel for Forging,” Wear, Vol. 255, No. 7-12, 1985, pp. 1444-1454. 